\title{
Doctoral Study-Key to What?
}

Doctoral study can improve one's ability to function well in an academic situation; this is equally true of librarianship as of other older disciplines. At the present time much doctoral level study and research interworks with other disciplines. It can be said in many ways to open doors, but some of these doors can lead to activities that are more psychically and professionally rewarding than others. Seekers of the doctorate should ponder the reasons for their search.

D OCTORAL STUDY is the key to many doors, some of which will not open readily without it. Research and teaching in higher education are the two most relevant career potentials, with a variety of collateral benefits available, including position, status, tenure, and all of the rights, responsibilities, privileges, and honors thereunto appertaining. The degree carries with it a certain aura in government, business, and industry, and although the title, "Doctor," may on occasion raise false expectations in respect to setting broken bones and reviving the faint, it is thought to do something for the holder as a public figure when trying to make reservations or establish credit.

Doctorates, like other keys, come in many combinations. The $\mathrm{PhD}$ in physics opens a high-priced suite in the intellectual establishment up near the front door, close to chemistry and mathematics. The doctorate in economics is across the hall on the social sciences side, with a hot line to Washington. History is there too, often respectful to tradition (less so when informed by other

Neal Harlow is dean of the graduate School of Library Service in Rutgers University. This paper was read to the joint meeting of ALA's Junior Members Round Table and the American Association of Library Schools in Kansas City on June 26, 1968. disciplines), with pictures of the illustrious dead plastered over the walls. Political science, sociology, statistics, psychology-all have established recognized positions. Not always does the family of accepted disciplines dwell together in peace and harmony, one branch after another gaining the ascendancy as unscholarly influences-government support, political attention, current events, supply and demand-affect their images and salaries. The professions are mostly segregated in bright ghettos, with separate and sometimes equal credentials but a variety of differentiating labels: EdD, JD, MD, DLS, DD. (And the system is of course incomplete without its irrational element, the anti-system of non-doctorates, LittD, LLD, LHD, and DSc, honoris causa, awarded without academic criteria.) Librarianship is both inside and outside the establishment, having developed its own minimum disciplinary content but being dependent for much of its context and methodology upon other substantive fields. A good many interconnecting doors and open transoms exist among the subject areas, but none calls for more hospitality to its friends, neighbors, and relatives than librarianship, one of the now earnest aspirants to intellectual parity.

In librarianship, not only librarians but professors of librarianship have tend- 
ed to be practitioners whose concept of the field has not recognized intellectual discipline or scientific research as essential ingredients. This isolation from the scholarly world is inbred, going back to the period when the self-made librarian turned into the self-made teacher who had the personal qualifications and practical experience but no tie to the world of learning-a condition which was not necessarily rectified by eventual university affiliation. It has been perpetuated by the librarian's continuing lack of clarity in identifying his own distinctive area of competence as distinguished from the subject fields to which it is applied, thus confusing him about the sources from which his special knowledge derives. To many, history and literature have been the most familiar studies and have therefore seemed the most relevant, but over the years history's cumulative and narrative techniques (which librarians have characteristically applied)-providing facts without hypotheses-have contributed little to our theory or systematic knowledge. Recent association with the sciences has led to studies in such areas as systems analysis, computer science, linguistics, and psychology and has stimulated new interests and attitudes. Equally exciting intellectual, methodological, and technical innovations are being carried over from social research, opening whole new library worlds for exploration. Findings in all of these areas can infuse the spirit and content of research into the profession and dramatically affect the professional teacher. It is the function of the doctorate and of a university to unlock doors to new knowledge; professional schools-law, medicine, social work, librarianship-which do not have or are not developing this capability hardly warrant a university environment.

Opening the door to research competence through doctoral study means more than making the individual a good research methodologist, and an advanced degree ought not to be conferred upon persons who are ignorant of the issues involved. But although the librarian's concerns are specialized, they often prove to be new focuses upon problems which are already known to older disciplines and are therefore equally pertinent and attractive to them. We go to the statistician for needed assistance, and he not only discovers that our problems are fascinating in their own right but that they also suggest new possibilities for him. We consult a geographer, and he quickly replies that the proposed study is in his field, not ours, and he wonders why he did not think of it first. Or we make a joint research proposal with urban studies, and it does not matter whether they help us or we them, the study and findings are equally important to both. And the computer specialist adds librarianship to his academic qualifications to fill a basic gap in his professional education.

But although a librarian can get help from a specialist in methodology, and often needs it, he cannot develop a research problem without the capability to design his own research procedure, collect and analyze the data, and draw appropriate inferences. A knowledge of statistics enables him to reduce large amounts of actual or potential data to comprehensible form, aids in the study of relationships and the testing of hypotheses, assists in making adequate inferences about the findings, and tells something about their reliability. ${ }^{1}$ There is no substitute for a knowledge of statistics, and, fortunately, modern statistics is full of intellectual excitement. Acquaintance with a variety of research techniques and with computer and programming theory are likewise essential. No one can collect the data and lay the methodology on afterwards.

A fundamental part of the process of

1 Fred N. Kerlinger, "The Doctoral Training of Research Specialists," in Teachers College Record, LXIX (February 1968), 477-83. 
admission to the field of research is a period of actual apprenticeship to a seasoned and responsible research professor. Of all the requirements, this may be of the most practical importance; and the main reason that research does not "take," that doctoral students do not become fascinated with research and develop into competent and productive research people, may be that they have not served under sufficiently capable, committed, and communicative faculty. Learning methodology, even in a rich substantive context, without the opportunity to develop competence and thereby acquire freedom and confidence in its use opens the door to the promised land but does not pass the candidate through. The doctorate is the key to continuing discovery, and if the process does not prove to be the most absorbing, significant, and enriching experience in the student's life, either he or his professors were somehow not up to it.

A working knowledge of research, built upon a sound substantive basewith whatever other qualifications individual institutions may specify-is the key to academic appointment. And with research-oriented teachers, the schools are more likely to lead the profession than to follow it, this being why the universities may even seem to overdo their emphasis upon the doctorate as the minimum qualification for academic advancement. The attitude and habit of research alter the outlook of faculty, and the character and level of graduate education are vitally affected. Doctoral study may not be an open sesame to academic achievement (there are other requirements), but successful academic careers are unlikely without it.

What about the $\mathrm{PhD}$ as a passkey to administrative position in the scholarly library? The degree is evidence the holder has the same kind of stamina as other academic people and a similar background in research techniques, suggesting that he will be sympathetic to their needs (if not to those of the more inarticulate student). It is a common denominator of academic existence, giving the librarian a kind of parity with faculty, a higher acceptance rating with appointment committees, and a status which his later performance will not too adversely modify. But as it requires the use in a substantial way of the competencies he has developed through doctoral study, it may be like specifying nursing credentials for an airline hostess or a librarian's qualifications to preside at a loan desk. It should give the head librarian a clearer understanding of the objectives of practice, a distrust of many of the assumptions upon which practice is based, an urge to study new approaches and to guide investigation, and an administrative organization which encourages library research and experimentation. If, however, his qualifications for research are not called upon in a fairly sustained way, requiring the $\mathrm{PhD}$, pro forma, for administration, is a waste of precious manpower. If the DLS is indeed a professional rather than a research degree, perhaps without the rigorous research requirement, its relationship to administration is more obvious and meaningful.

Doctoral study is indeed the key to many doors, some of which will not open readily without it. Research and teaching in higher education are indeed the two most relevant career potentials, with a variety of collateral benefits available, including position, status, tenure, and all of the rights, responsibilities, privileges, and honors thereunto appertaining. The key will also open doors not necessarily intended because in places it outranks all others. Some uses, however, are more appropriate than others, more productive, currently more essential, even more honest professionally. Holders of the doctorate will want to be sure not only that the key fits a lock but also that it opens the door prescribed in the architect's specifications. 